\title{
Analysis of the Influencing Factors of Tourism Income
}

\author{
Zhang $\mathrm{Xu}^{1, \mathrm{a}}$ \\ ${ }^{1}$ School of Economics, Shanghai University \\ Shang Hai
}

\begin{abstract}
The contribution of tourism income to China's economic growth has become increasingly prominent. The composition of tourism income has shown a diversified trend. The development of the downstream industry chain driven by tourism has also been continuously extended and integrated. This paper uses the data from China Tourism Statistical Yearbook to analyze the main constituent elements of tourism income, and analyzes the impact of these changes on the overall income of the tourism industry. The article constructed a multiple linear regression model to explain the changing factors of tourism income, and tested and optimized the model at the same time. Finally, the author proposes relevant policy recommendations.
\end{abstract}

Keywords-Tourism income; Influencing factors; Model analysis; Policy suggestion

\section{INTRODUCTION}

In the past two decades, China's tourism industry has achieved vigorous development with the support of the country and has gradually formed a good situation of "great tourism, great industry, and great development". Industrial scale and industrial coverage continue to grow, while at the same time seeping and integrating with each other. The development of the domestic tourism industry thus entered a new era and a new journey. The related downstream industries developed from the tourism industry mainly include: catering industry, hotel service industry, transportation industry, consumer goods industry and entertainment industry. Tourism has made important contributions to the development of the national economy, and its importance in GDP growth has also gradually increased. According to the "China Tourism Statistical Communique" data, domestic tourism revenue has grown steadily overall. From 2006 to 2016 total domestic tourism revenue increased rapidly from RMB 262.97 billion to RMB 39400.9 billion, and the average annual growth rate was nearly $20 \%$. It is expected that by 2020 , China will form the world's largest domestic tourism market and the world's largest outbound tourism market. The proportion of the value-added of tourism accounts for more than 5\% of GDP, and tourism is a strategic pillar industry of the national economy.In view of the important role of tourism in promoting economic growth, promoting social consumption and employment, in the "12th Five-Year" development plan of various regions, tourism is positioned as a strategic pillar industry or pillar industry by the provinces and municipalities in China, and set up a leading tourism development organization led by Party committees or government leaders. On the other hand, urbanization is one of the national strategies of China's social and economic development. Especially since the beginning of the 20th century, China's urbanization has made rapid progress and has become the leading force in economic development. Urbanization is also one of the important measures taken by the new government to transform the domestic economic structure, and tourism and urban development are closely related. On the one hand, the city is the main gathering place and carrier of tourists. Tourism urbanization is a notable feature of tourism expansion. On the other hand, the development of tourism has injected power and vitality into the city, and tourism has played a significant positive impact on the improvement of urban comprehensive strength, the operation of urban brand and the improvement of urban human living environment. For a long time, a large number of theoretical and empirical studies have confirmed that the tourism industry has contributed actively to the development of the urban economy in the aspects of foreign exchange income, financial income, employment opportunity creation and infrastructure improvement. But we have to admit that the scale of mass tourism is expanding, and the rapid growth of tourism has hidden some urgent problems in the city's economic growth, environmental protection, and the rapid development of China's tourism industry. The primary problem is that the tourism resources of our country are not solid enough. At present, China's natural resources and human resources have not been fully developed, and there is a big gap between the East and the West in terms of resource development. The development of tourism resources in the Midwest and the improvement of infrastructure still need to be further improved compared to the East, and some other problems, such as tourism environment and the lag of traditional tourism, have also affected the growth of China's tourism industry. Studying the factors that affect tourism income has important implications for the improvement and development of the tourism industry chain and for the economy under the "new normal" background. This paper uses the data from the 1995-2016 "China Tourism Statistics Yearbook" and the 2016 "China Statistics Abstract" to analyze several important factors that affect tourism revenue and draws corresponding conclusions. 


\section{EMPIRICAL MODELS AND RESEARCH METHODS}

\section{A. Variable Selection}

This article selects the following factors that affect tourism income as variables of the model:

\section{1) Total number of tourists (totnum)}

China's domestic tourism groups are the biggest promoters and consumers of the tourism industry in theory, and are the most important factors influencing tourism revenue. The continuous increase in the number of tourists also continues to drive the increase in tourism consumption, which has led to an increase in tourism revenues. It is generally believed that there is a positive correlation between tourism income and the number of tourists. Therefore, this article selects the total number of tourists as an explanatory variable to reflect the factors that affect tourism income.

\section{2) Per capita consumer spending (consp)}

The status of social and economic development is an important factor affecting residents' trave. Many studies at home and abroad have shown a positive correlation between economic conditions and tourism development. The better the social and economic development, it will increase the per capita disposable income. Whereas the increase in per capita disposable income will increase tourism consumption, tourism consumption expenditure will account for more of the total consumption. As a result, the revenue generated by the tourism sector has increased. Therefore, this article selects per capita consumption expenditure as the second factor that affects tourism income.

\section{3) Railway mileage (railmile)}

The development of modern tourism is closely related to transportation and transportation, and the development of transportation industry is bound to bring about the prosperity of tourism. The convenience of transportation is an important symbol to measure the development and development of the tourism industry. The tourism industry uses its economic radiation function to promote the development of regional economy and increase the employment position, and transportation is not only a basic facility for regional economic development, but also a prerequisite for the development of tourism industry. It plays an important role in the development of tourism resources and the improvement of service level.With the vigorous construction of our country's income $=\beta 0+\beta 1$ totnum $+\beta 2$ consp $+\beta 3$ railmile $+\beta 4$ travnum $+\beta$ hotelnum $+\mu$.

Among them, income represents tourism revenue, totnum represents total tourism, consp represents per capita consumer spending, railmile represents railway mileage, travnum represents travel agency, hotelnum represents star-rated hotels, and $\mu$ represents residual items.

The paper examines the impact of the selected five explanatory variables on tourism income by constructing the econometric model described above. infrastructure, public transportation routes cover a wide range and the safety index has improved significantly. In particular, the railway network has basically covered all parts of the country, and the operational efficiency and technical level of China's high-speed rail have been uniformly praised in the world. As a result, the railway mileage can largely reflect a country's land transport capacity. In order to avoid the problem of multicollinearity of the model, this paper selects the railway mileage as a relevant indicator of the transportation capacity. This factor can make it more willing for travelers to choose long-distance travel, and the spread of the railway network can more easily reach more distant destinations. Therefore, the railway mileage factor will also have some impact on tourism revenue.

\section{4) Number of travel agencies (travnum)}

Travel agencies act as information guides for travel before travel and as service stewards during the travel process. The thriving tourism industry has spawned many travel agencies that provide travelers with travel services. With the increasingly fierce competition in the tourism service industry, the service quality and quality of the industry have been greatly improved. Therefore, the huge number of travel agencies provides passengers with more choices to meet different needs of the traveler group, and has a more direct impact on tourism revenue. Therefore, the article selects the number of travel agencies as one of the explanatory variables influencing tourism revenue.

\section{5) Star hotel (hotelnum)}

The star-rated hotels need the review and assessment of relevant departments in China, and they can only be granted relevant star qualifications after passing the review. It can, to a large extent, reflect the ability of the tourism industry to receive tourists. In order to improve the passenger travel experience travel, Star Hotel is the passenger travel more choices of accommodation and eating places. Therefore, the number of star-rated hotels is one of the important factors considered by travelers. At the same time, it is also one of the important factors affecting tourism revenue.

\section{B. Model Settings}

This article selects a multiple linear regression model and builds the following model based on the variables selected above:

\section{Data Sources}

According to the "China Tourism Statistics Yearbook" from 1995 to 2015 and the "China Statistical Abstract" from 2015, this paper screens and compiles the data on the tourism income and related influencing factors(including the total number of tourists, per capita consumption expenditure of residents, railway mileage, number of travel agencies, and number of hotels) from 1994 to 2016. 


\section{Model Estimation}

The statistical software stata14 is used to perform the least square estimation of the above-mentioned model, and the regression result is as follows:

$$
\text { income }=-13273.4+738.3 \text { totnum }+0.4031 \text { consp }+1801.7 \text { railmile }-0.3845 \text { travnum }-0.014 \text { hotelnum }+\mu .
$$

The R-squared of this model is 0.9949, has a higher coefficient. At the same time, the $\mathrm{F}$ statistic is 579.83, indicating that the equation is significant at the $5 \%$ significance level. The positive impact of total tourism on total tourism revenue is very large, which is in line with our forecast. The railway mileage also has a certain positive impact on total tourism revenue. Per capita consumer spending has basically no effect on total tourism revenue. However, the results show that the symbols of railway mileage and number of star hotels are contrary to expectations. This shows that the set model is likely to have serious multicollinearity. Therefore, the model needs to be further tested for multicollinearity.

\section{E. Multicollinearity test}

Using software stata14, the following correlation matrix is obtained:

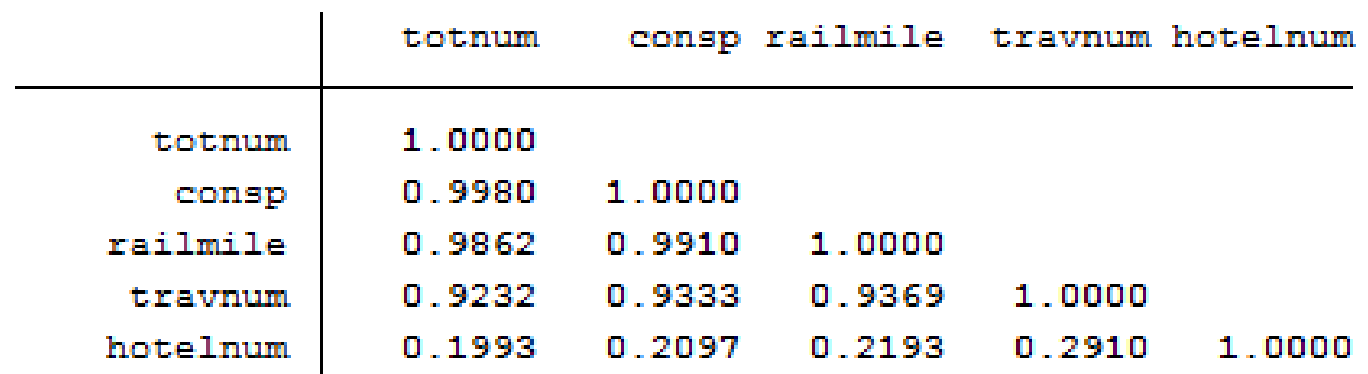

Fig. 1. Correlation coefficient matrix.

It can be seen from the correlation coefficient matrix that the correlation coefficient between each explanatory variable is high, and there is indeed a multicollinearity problem before the explanatory variable.
1) Multicollinearity correction

Use software stata to establish a linear relationship between income and totnum, consp, railmile, travnum, and hotelnum, and obtain the following regression results:

$$
\begin{gathered}
\text { income }=-4680.419+906.8328 \text { totnum. } \\
\text { income }=-4002.836+1.7721 \text { consp. } \\
\text { income }=-38187.14+5996.036 \text { railmile } . \\
\text { income }=-5594.655+0.9638 \text { travnum. } \\
\text { income }=-8006.06+0.0365 \text { hotelnum. }
\end{gathered}
$$

From the results, we can see that the $\mathrm{R}^{\wedge} 2$ of the above regressions are: 0.9762, 0.9688, 0.9481, 0.7507, 0.593.

Therefore, the stepwise regression will be based on totnum, Obviously, tourism income is influenced by the total number of tourists (totnum).

$$
\text { income }=-4680.42+906.83 \text { totnum } .
$$

In the first step, travnum was introduced into the initial model, and the $\mathrm{R}^{\wedge} 2$ was further improved, and the t-test was passed.

$$
\text { income }=-3455.389+1168.735 \text { totnum-0.344travnum. }
$$

In the second step, the variable railmile is introduced into the model, and the t-test can also be used to show that each coefficient is significant.

$$
\text { income }=-14738.7+919.4089 \text { totnum-0.4099travnum+2038.636railmile } \text {. }
$$

The third step, introducing the variable hotelnum in the model, each coefficient can pass t test and significant; income $=-15043.32+893.72$ totnum -0.3737 travnum +2083.845 railmile- 0.014 hotelnum . 
In the fourth step, the variable consp is introduced in the model, and the p-value of consp is much larger than 0.05 . The $\mathrm{t}$-test cannot be passed, and $\mathrm{R}^{\wedge} 2$ has almost no change before adding the explanatory variable, so the variable can be eliminated in the model.

Based on the above results, the new fitting model should be: income $=-15043.32+893.72$ totnum- 0.374 travnum +2083.84 railmile- 0.014 hotelnum .

\section{F. Heteroscedasticity test}

Test the heteroscedasticity of the new model after modifying the effect of multicollinearity, and use the BP test to test for the presence of heteroskedasticity. According to the test results, the $\mathrm{P}$ value is higher than the significance level of 0.05 , so we cannot reject the original assumption of homoskedasticity. Therefore, there is no heteroskedasticity in this model.

In summary, the final model is equation (12):

\section{G. Autocorrelation test}

The DW test was used to determine whether there was an autocorrelation in the error term and the test result was checked against the DW. The result showed that when $\mathrm{k}=4$ and $\mathrm{T}=21$, $\mathrm{dw}=1.26$ was between $(0.93,1.81)$. It cannot be determined whether there is autocorrelation.

income $=-15043.32+893.72$ totnum-0.374travnum +2083.84 railmile-0.014hotelnum

\section{CONCLUSION AND SUGGESTION}

Through the multiple linear regression model established above, the main factors influencing the domestic tourism revenue include the total number of tourists, railway mileage, number of travel agencies, and number of hotels in the stars.

As can be seen from the data, when other factors remain unchanged, the total tourist revenue can increase by RMB 89.372 billion for each additional 100 million person-times of travel, which means that for every additional person to travel, the tourism income increases by 893.7 yuan; When other factors remain unchanged, the railway mileage increases by 10,000 kilometers, and tourism revenue increases by 208.384 billion yuan. It can be understood that the development of the transportation industry makes people travel more convenient, people are more willing and able to go to the favorite tourist attractions, so the development of the transportation industry has a positive effect on the tourism industry. Therefore, the government should increase the construction of transportation infrastructure and its supporting facilities. At the same time, it promotes the modernization, humanization, and informationization of the management and operation of the transportation sector, and accelerates the enhancement of user experience and service efficiency in the transportation industry. Diversified modern transportation services can meet the full range of travel needs of most travelers while providing personalized services for a small number of travelers.

For the total number of travel agencies and the total number of star hotels, although the former passed the t-test, the correlation coefficient between the two is negative. Travel agencies and star-rated hotels have many similarities in the development of tourism industry in different places. This article will put them together for analysis, and compare and discuss their impact on the development of tourism. From the traditional economics theory, When the product has a certain substitution relationship, the more representative manufacturers and more products are produced, the more the quantity of products in the low end product space will increase, so the market competition relationship becomes more and more fierce, which causes the market price to reduce, making the manufacturer's profit space smaller and smaller, which is often said to be " Vicious circle, disorderly competition". However, if the product has a certain complementary relationship, then the situation will be the opposite. The more production products, the products of different quality will increase, the market will have positive linkage effect, the profit will be further increased, and form the situation of "opening up the market and invigorating the economy". However, due to the development of the tourism industry, the travel agencies and star hotels all over the country grow brutally, and the market entry threshold is low, so the supervision is more difficult. The competition in the same industry has seriously weakened the complementarity of the two products, coupled with the recent frequent exposure of the "Black Travel Agency" and "black hotel events" to the reputation of the tourism industry. From this point of view, the brutal growth of the number of travel agencies and star hotels will have a negative impact on the tourism industry around the country. Therefore, the major tourism provinces should improve the entry threshold of travel agencies and star hotels, strengthen supervision and fight against illegal and criminal behavior, in order to promote the rapid and healthy development of local tourism. The remaining explanatory variables failed the t-test and did not have significant economic significance.

\section{Inadequacies:}

First, the DW test does not determine whether there is autocorrelation, and should continue to explore on the basis of mastering more knowledge;

Second, ignoring some other influencing factors, international tourists visiting China are also an important part of China's tourism industry.

In addition, there are tourism consumption of rural residents, the increase of civil aviation mileage and the level of price, etc. In fact, rural areas have great potential, and the state should gradually support them. 


\section{REFERENCES}

[1] GAO Nan,WANG Linyan,MA Yaofeng,Zhang XINCHENG,LIU Chuchu. Urbanization Response Mechanism of World Cultural Heritage Attachment Place in the Driving of Tourism:A Case of Pingyao Ancient City [J]. Economic Geography,2017,37(04):198-207.

[2] GAO Yang,MA Yaofeng,LIU Junsheng. Study on the coupling coordinative development and types among tourism,urbanization and ecological system:a case study of Beijing-Tianjin-Hebei area [J]. Journal of Shaanxi Normal University(Natural Science Edition),2016,44(05):109-118.

[3] WANG Jingrong. An Empirical Research on Measuring Carbon Dioxide Emissions from Urban Tourism: A Case Study of Sheng[J]. Geography and Geo-Information Science,2012,28(05):104-109.

[4] CAO Fangdong,HUANG Zhenfang,WU Jiang,ZOU Wei .Measure of City Tourism Performance System Coupling Assciation and Forecast--A Case Stuy of the Pan-Yangtze River Delta [J]. Economic Geography,2012,32(04):160-166.

[5] YANG Changpeng. Research on the Relationship between Urbanization Level and Tourism Development in Guizhou [J]. Guizhou Social Sciences,2012(01):76-79.

[6] WANG Deyin,CHEN Tian,WANG Hao.An Analysis on Mechanism and the Wyu of Inproving Quality of Urbanization of Development Zone based on Promotion of Tourism-a case Study of Suzhou Industrial[J]. Human Geography,2011,26(01):123-128.

[7] WANG Yan,WANG Zhe. An Analysis of Industry Connection and Industry Sprawl in Tourism Industry in Xinjiang Based on Input-Output Model [J]. Journal of Arid Land Resources and Environment,2008(05):112-117.

[8] Zou Zaijin. A Study on the Theory of Operational Types of Regional Tourist Industries [J]. Geography and Geo-Information Science, 2007(05):100-104.

[9] LING Yihua,,MA Xialong. Grey Relational Analysis of Influence Factors on Tourism Development [J]. Human Geography,2006(02):37$40+44$.

[10] FANG Yelin,HUANG Zhenfang,LI Donghe,WANG Fang. The Measurement of Chinese Provincial Tourism Developing Efficiency and Its Spatio-Temporal Evolution [J]. Economic Geography,2015,35(08):189-195.

[11] GE Quansheng,XI Jianchao. Strategic choices of regional tourism under the new normal of China's economic growth [J]. Progress in Geography,2015,34(07):793-799.

[12] LI Rui,GUO Qian,HE Ji,WU Dianting,YIN Hongmei,YE Qian. Spatial temporal characteristics of development efficiencies for urban tourism:a case study of three urban agglomerations in the Bohai Rim[J]. Progress in Geography,2014,33(06):773-785.

[13] LI Rui,WU Dianting,YIN Hongmei,HU Hao,ZHU Taoxing,WU Mengshan. Comprehensive measurement and spatial characteristics of development efficiency for urban tourism in eastern China:A case study of four coastal urban agglomerations [J]. Geographical Research,2014,33(05):961-977.

[14] ZHONG Jiayu,LIU Siwei,XIONG Xi. Analysis on the Regional Difference of Coordinated Development between Tourism and Urbanization[J]. Economic Geography,2014,34(02):187-192.

[15] SHUN Gennian,PAN Pan. Regional Differences and Influencing Factors of Tourism Development in Shidi City, Shaanxi Province [J]. Journal of Arid Land Resources and Environment,2013,27(11):184-191. 